Marketing in Asia Group

\title{
The Role of Relationship Conflict and Mindfulness in the Consequences of Task Conflict
}

\author{
Umar Shahzad \\ Air University School of Management, Air University Islamabad, Pakistan \\ Mumtaz Ali Memon \\ Air University School of Management, Air University Islamabad, Pakistan \\ Shahzad Khurram \\ Air University School of Management, Air University Islamabad, Pakistan
}

Kim Lim Tan

Human Capital Leadership Institute, Singapore

The University of Newcastle, Singapore

\begin{abstract}
To date, there is a lack of research that explains the linkages between relationship conflict, task conflict, team mindfulness, perceived stress, and social undermining. In particular, little attention has been paid to these constructions in the context of the virtual workplace. The present study attempts to fill this research gap. The aim of this research is to examine the mediating role of team mindfulness between task conflict and perceived stress. Additionally, it also investigates the moderating role of relationship conflict on task conflict and outcomes including perceived stress and social undermining. Using a structured questionnaire, data were collected from 230 respondents working in virtual work teams of different information and communication technology organizations in Pakistan. The results have shown a significant indirect effect of task conflict on perceived stress through team awareness. Although relationship conflict moderates the relationship between task conflict and perceived stress, it has no impact on the relationship between task conflict and social undermining. The findings of this study have a number of implications for research and human resource managers.
\end{abstract}

Keywords: Relationship Conflict; Mindfulness; Task Conflict; Perceived Stress; Social Undermining 


\section{Introduction}

Team research often study into task conflicts and understand how it affects team performance. By definition, task conflict has been described as task-related disagreements which, as well as having detrimental effects, may encourage the exchange of ideas and improve decision quality (Jehn \& Mannix, 2001). Task conflict increases the cognitive load of individual employees involved in such a task related conflict. It detaches the thinking process from positive intentions towards negative ones and reduces the ability of the employees to separate task-related stimuli from personal stimuli (Simons \& Peterson, 2000). Therefore, people may interpret task conflict as personal dislike and personal criticism that they receive (Greer et al., 2008) and at times, they may take it as a challenge for their competency which changes the focus of task conflict towards relationships (Tidd et al., 2004). Task conflict at the workplace may possibly lead to the relationship conflict at the workplace. This may be either individual relationship conflict or relationship conflict between the teams that are represented by those individuals. When such conflicts happen, it can be the source of individual deviant behaviours that results in negative individual and work outcomes (Wu et al., 2015). In response, researchers have begun to investigate how to reduce the risk of task conflicts turning into relationship ones.

Despite the burgeoning research, gaps remain. Firstly, there is a lack of study explaining how relationship conflict play a role in adding to perceived stress and social undermining at the workplace for employees working in virtual teams. Literature has identified that social context acts on relationship conflict and individual employees working in teams may get effected by social undermining due to different reasons (Hershcovis, 2011). Efforts of employees to maintain meaningful relationship in team may stimulate them to systematically process moral issues as per their individual interpretation and at times, it gets difficult for them to respond in morally desirable ways (Van Kleef, 2010). This kind of a situation may lead to perceived stress and social undermining in the employees working in a team. Perceived stress may be a stimulant to a variety of health challenges for individuals and teams. Stress of employees at the workplace is linked with changes in cognition, behaviours and emotions. However, many of existing studies have focus on how task conflict turns into relationship conflict, and not how relationship conflict may intensify the perceived stress and the feeling of social undermining within the employees. Without which, we argue that the understanding of role and task conflict are incomplete which this study addresses this gap by incorporating relationship conflict as a moderating variable in this model.

At the same time, this study addresses the second gap by addressing the role of team mindfulness in the relationship between task conflict and perceived stress. As Yu and Zellmer-Bruhn (2018) elucidated, mindfulness is "a shared belief among team members that their interactions are characterized by awareness and attention to present events, and experiential, non-judgmental processing of within-team experiences". They perceived mindfulness as a protection against multilevel conflict handling processes while the scientific literature generally scrutinized mindfulness as the intra-psychic aspect at individual level (Good et al., 2016), or as an interrelated set of practices at organizational level (Sutcliffe et al., 2016). Mindfulness also relates with teamwork (Karlin, 2018), leader flexibility (Baron et al., 2018), social learning and organizational learning (Cacioppe, 2017), creating positive value (Dietz et al., 
2017), ambidexterity (Turner et al., 2016), turnover (Dane \& Brummel, 2014), relating employees with the performance of organization (Dane, 2011), mindful organizing (Wolff, 2014) and work related decisions (Hafenbrack et al., 2014). However, team mindfulness is often studied at individual level but not at team level. As mindfulness at the team level differs structurally from individual mindfulness $(\mathrm{Yu}$ \& Zellmer-Bruhn, 2018) this study will advance the body of knowledge by examining how the team mindfulness can act in addressing such a situation of task conflict present at the workplace (Davidson \& Kaszniak, 2015).

Lastly, increasing globalization and availability of information technology enables today's organizations to collaborate remotely among team members (Algesheimer et al., 2011). People around the globe organize virtual teams to solve difficult problems through electronic communication. With a global virtual team, cultural norms and linguistic idiosyncrasies make it more difficult for employees to participate, make quality decisions, and be satisfied with those decisions. If not managed well, a global virtual team can struggle with performance because of inherent categorization of subgroups within the team, giving rise to role and task conflicts (Stahl et al., 2010). While managing virtual teams is not a new phenomenon, but extant studies have revolved around team processes, multiculturalism, coordination effectiveness, trust and team cohesion. Little pay attention on the role of team mindfulness (Winkler \& Bouncken, 2011). Against the backdrop of growing popularity of virtual teams, this study seeks to fill a gap by extending the impact of team mindfulness and role conflicts on virtual teams' perceived stress and social undermining.

Collectively speaking, the outcomes of this study has the potential to contribute to the body of knowledge on three endemic interpersonal processes including conflict for individuals working in virtual setup of ICT based organizations in Pakistan and its subsequent effect on perceived stress and individual social undermining (Boyle et al., 2017; Brisbon \& Lachman, 2017; Rayan et al., 201; Xu et al., 2017). This study would add significantly to existing literature as no prior study addressed the impact of team mindfulness on perceived stress and for the effects of relationship conflict as a moderating variable and hence its indirect impact on the perceived stress and social undermining for virtually and digitally connected workforce.

The underpinning theory is explained in the next section, which is followed by the development of several research hypotheses. A research model is proposed based on these hypotheses. Following this, we describe the methods used throughout the present study, including measurement scales, and sampling design. We then describe both the analysis and results, followed by a detailed explanation of the findings, including their implications. The last section, highlights some of the limitations of this research and provides a number of recommendations for future studies.

\section{Theoretical Underpinning}

Studies into the role of team mindfulness has pointed towards the relevance of individuals leveraging on resources to mitigate against the negative effects arising from work (Tan et al., 2019). In this regard, we argue that the job demands-resources (JD-R) theory is particularly relevant for this study. The JD-R theory is a widely used theory that explains how the interplay of resources and demands forms either job 
motivational outcomes or job strain outcomes among the employees (Grover et al. 2017). The key tenant within the JD-R theory spotlights the imbalance in either one of them, with excessive demands or insufficient resources will trigger a health impairment process, causing an individual to experience feeling emotionally exhausted, cynical and discrediting all former accomplishments (Bakker \& Demerouti, 2007). Similarly, the presence of resources or the absence of strains provide individuals with the motivation to fulfil their work requirements (Bakker \& Demerouti, 2017).Following the arguments in JD-R theory, the conceptual framework (see Figure 1) postulates that in the absence of resources, role conflicts and task conflicts will inevitably lead to social undermining and perceived stress. However, mindfulness, as a personal resource, have the motivation potential that mitigates the effect.

\section{Literature Review}

\section{Team Mindfulness}

In teams, "mindfulness" is an interpersonal, collective and cognitive phenomenon happening in interactions among the team members (Vogus \& Sutcliffe, 2012). From the literature, several definitions arose on what constitute team mindfulness. Marks et al. (2001) define "mindfulness is a rising, shared intellectual state which colleagues create through involvement with the group". Emerging states and procedures are connected due to mindfulness, as developing states are the result of group communication and influence ensuing associations (van Knippenberg et al., 2013). For Carter et al. (2018), team mindfulness was a common property of team experience which separates it from the individual mindfulness. For Morgeson and Hofmann (1999), mindfulness paradigms include both the individual and team level but their composition varies. They suggested two elemental content dimensions of mindfulness as; "(1) present focused attention and consciousness about what is happening at present and (2) experiential processing- non-judgmental, receptive and practical dispensation". Current moment refers to the fact that what is going at present rather than thinking about the past issues or about the future (Smallwood \& Schooler, 2015), while there is also the belief that mindfulness includes paying consideration to purpose of an activity (Dreyfus, 2011).

Putting these definitions together, we can synthesize that team mindfulness is a common perception of the members working in the team about the thinking pattern that emerges from interpersonal interaction as team members interact with each other (Bettenhausen \& Murnighan, 1991). Team mindfulness defends against the negative interpersonal interactions in team processes. Yu and Zellmer-Bruhn (2018) defined "team mindfulness as a shared belief among team members that team interactions are characterized by awareness and attention to present event, and by experiential, nonjudgmental processing of within-team experience" (Sutcliffe et al., 2016). Sometimes at the workplace, few team members remain connected for task related communication and ignore some of the other colleagues. Such communication barrier is detrimental for the performance of team members and such process requires to be reversed. Team members often get judgmental to defend their own stance without giving a broader view to the stance of another team member. But, if the members of the team remain united, then the judgmental cognitive processes positively add to the 
performance and effectiveness of a team. For Weick and Roberts (1993), collective action with mutual understanding and shared brainstorming to act positively for the team contributes positively through team mindfulness (van Knippenberg et al., 2013). As a result of positive reinforcement in the thinking process of team members, team mindfulness becomes a source of inspiration for the members working in that team (van Knippenberg, van Ginkel \& Homan, 2013).

That is to say, mindfulness enables individuals to have a better and smarter view of the environment around them especially with reference to team. It helps in decision making in a collective environment. People remain more engaged and aware about the dynamics of current view and about the requirements of the team (Sell, 2018). For Baron et al. (2018), individuals' ability to respond to the needs of the outer environment is another aspect of team mindfulness. In team mindfulness, individuals remain engaged with the collective effort. Consequently, it improves cognitive functions which are perilous for routine organizational activities, mindfulness works as a form of positive intervention for the employees' interpersonal interactions and individual cognition. Management researchers are still studying that how mindfulness operates at the team level (Hulsheger, 2015; Good et al., 2016; Yu \& Zellmer-Bruhn, 2018). Therefore, it is important to have a broader understanding of how the team mindfulness acts at different levels in the organizations.

\section{Mediation Effect of Team Mindfulness on Task Conflict and Perceived Stress}

In general, task conflict enhances employees' cognitive load and it becomes difficult for the employees to separate task related conflict stimuli from personal relationship related conflict stimuli (Simons \& Peterson, 2000). Hence, teams may take task conflict as a personal like or dislike (Greer et al., 2008) or assessment for the capability which diverts the attention from task conflict to relationship conflict (Tidd et al., 2004). High level of disagreements also adds to the bottleneck change in the team (Choi \& Cho, 2011) and decreases the perception that the members are open to unorthodox opinions (Tsai \& Bendersky, 2016). Weingart et al. (2015) explained that groups may translate task strife as a sign that contention is dug in, hoisting oppositional power and related negative feelings. Resultantly, groups with elevated levels of task differences have expanding reactivity and raising clash, in this manner expanding relationship strife.

Taking a leaf from this, it is also not difficult to realize that the presence of task conflict will give rise to perceived stress. Perceived stress is recognized as a precursor to a variety of health challenges for individuals and teams. Stress is linked with changes in cognition, behaviours and emotions. Lazarus and Folkman (1984) defined stress as "the perception that a situation or event exceeds coping resources". In specific terms, perceived stress incorporates feelings about the uncontrollability and unpredictability of one's life, how often one has to deal with irritating hassles, how much change is occurring in one's life, and confidence in one's ability to deal with problems or difficulties. It is not measuring the types or frequencies of stressful events which have happened to a person, but rather how an individual feel about the general stressfulness of their life and their ability to handle such stress. Individuals may suffer similar negative life events but appraise the impact or severity of these to different extents as a result of factors such as personality, coping resources, and support. In this 
way, perceived stress reflects the interaction between an individual and their environment which they appraise it as hostile and overwhelming.

Given this, we argue that team mindfulness gives progressively positive enthusiastic tone, centred around the present scenario, bringing down interruption from off-task considerations and exercises, attentional foundation to keep task objectives at the centre of thinking process and enables groups to see more noteworthy subtlety in practices (Good et al., 2016; Smallwood \& Schooler, 2015; Morrison et al., 2013). This prevents thinking on irrelevant stimuli (Slagter et al., 2011), simple errors and involuntary, narrowed experiential processing are less likely (Glomb et al., 2011), converting teams to less susceptible attribution errors and communication bias in a manner that personal and task stimuli remain separated (Hopthrow et al., 2017), accordingly, intense team capabilities are less probable to be understood as personoriented. Team mindfulness enhances understanding in an open, agreeable method for bringing down the personalization and response in the groups (Good et al., 2016) and this reduces the chances of relationship conflict (Amason \& Sapienza, 1997). Openness allows differences without hostility (Jehn, 1995), therefore mindful teams may see less restriction related with task strife. In entirety, mindfulness makes an inward into the group condition that is less inclined to relationship conflict by and large as it disturbs the association between task strife and relationship struggle. This restricts the exchange of consideration from individual towards task struggle and it remains the focal point of employee's responses and oppositional power and negative feelings happening with task conflict, in this way, constrain escalation towards the relationship conflicts.

Using the JD-R theory, we posit that team mindfulness acts as a personal resource that helps people to separate environment characteristics from their reactions to them, thereby reducing stress (Grover et al., 2017) Personal resources in the JD-R theory are unique individual employee attributes that affect how people use job resources to cope with job demands (Demerouti et al., 2001). These personal resources, such as resiliency, optimism, mindfulness, perceived control, and autonomy affect JD-R processes through perceptions of, and the ability to deploy, job resources. As explained earlier, being mindful means the ability attending to the present moment and achieving clear focus on the emotional demands and the greater understanding of them provided by non-judgmental awareness. Hence, team mindfulness could mitigate the negative impact of emotional demands on the experience of stress, leading us to the first set of hypothesis:

H1 Team mindfulness mediates the relationship between task conflict and perceived stress.

\section{Moderation Effect of Relationship Conflict}

Deviant behaviour in the individuals is one of outcome of negative interpersonal relationships (Wu et al., 2015). Hence, team relationship conflict may add to the outcome of social undermining at the workplace. Duffy et al. (2002) defined this phenomenon of social undermining as "a behaviour intended to hinder a worker's ability to establish and maintain positive interpersonal relationships, work-related success and favourable reputation". As highlighted earlier, social context also makes an impact on the social undermining and the relationship conflict (Hershcovis, 2011). 
Revoking temptations for keeping up great relations requires exertion, causing colleagues to encountering relationship struggle, making them less ready to perceive negatively and efficiently process moral issues to be ready to react in ethically attractive manners (Van Kleef, 2010).

Additionally, Jehn (1995) suggested that intra-group conflict is generated by team member incompatibilities and differences and its intensity may be different for task conflict and relationship conflict. Task conflict involves disagreement over policies, procedures and distribution of work while the relationship conflict primarily gets generated due to the differences of individual's personal values and perceptions at the workplace. De Dreu and Weingart (2003) stated that task conflict may often happen due to disagreement over tasks and at times, it may enhance the performance level of an employees at the workplace as employees often accept the challenging outcomes. However, relationship conflict is always detrimental and produces poor results (de Wit et al., 2012). Both the task conflict and relationship conflict are associated in many situations (Greer et al., 2008), but it is a difficult challenge to separate the benefits of task conflict and to evade relationship conflict for effective teamwork (Todorova et al., 2014). Hence, the relationship conflict often has detrimental effects and depends more on the intentions, will and behaviour of individuals' interpersonal relationships and cognitive traits (de Wit et al., 2012). In view of this, we therefore postulate that the presence of relationship conflict will further aggravate one's perceived stress and social undermining, leading us to the final set of hypotheses:

H2 Relationship conflict moderates the relationship between task conflict and perceived stress.

H3 Relationship conflict moderates the relationship between task conflict and social undermining.

Figure 1: Research Model

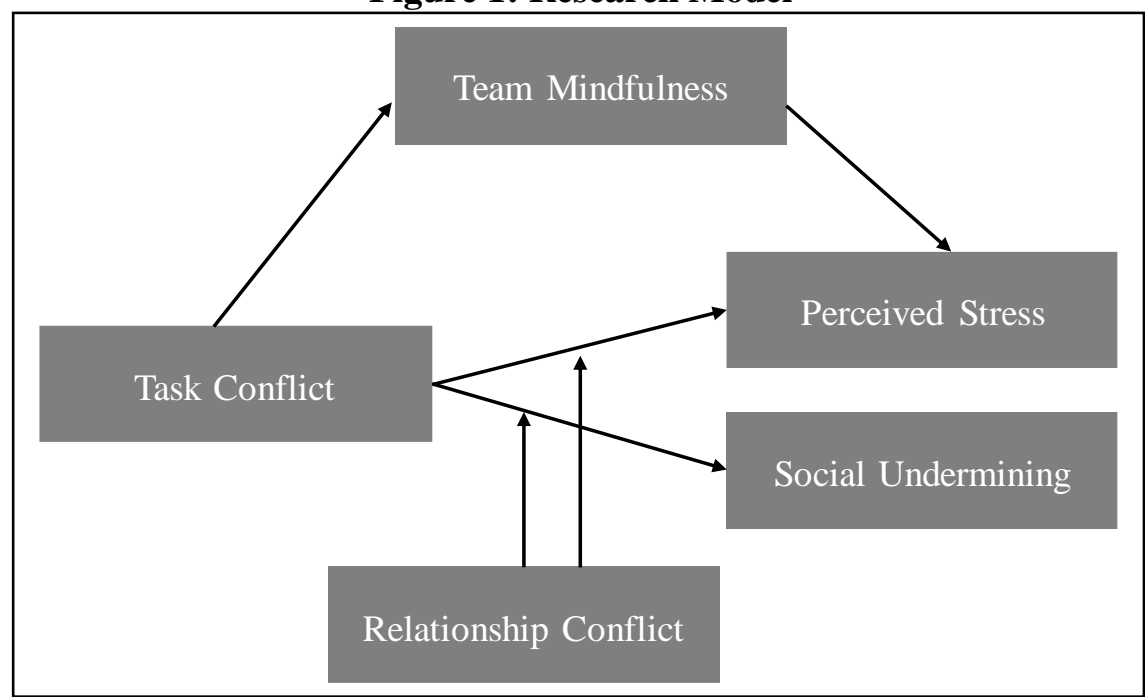




\section{Research Method}

Using purposive sampling, data was collected from organizations where team members primarily remain engaged with each other through virtual and digital sources of communication for most of the times. For this paper, data has been collected from 230 respondents. Data collection was done through personally administered questionnaires. Also, an email link was sent to the potential respondents and prior to that, they were briefed about the study. A total of 326 respondents were sent the questionnaire, out of which, 230 respondents filled the questionnaire with a response rate of 71 percent. IBM Statistical Package for the Social Sciences (SPSS) version 21 was used for data analysis. Additionally, SPSS Marco (Hayes, 2017) was used for mediation (Model 4) and moderation analysis (Model 1).

\section{Initial Screening}

Before main data analysis, the normality of data was checked using Skewness and Kurtosis scores. The results indicate that scores of all variables were within the satisfactory range, +1 and -1 (Hair et al., 2006). Also, outliers were examined using Mahalanobis distance. Obtained values did not show any significant outliers and all the values were in range (Hair et al., 2006).

\section{Measurement}

Measurement scales for all the variables were adopted from previous studies. For perceived stress, measurement scale of Sheldon Cohen and Gail Williamson (1988) was adopted that had 12 Items. For task conflict, measurement scale developed by Pearson, Ensley and Amason (2002) with 4 items was adopted. For relationship conflict, Pearson, Ensley and Amason (2002) developed a measurement scale of 5 items which was adopted for the present study. For team mindfulness, measurement scale developed by Lingtao Yu and Mary Zellmer-Bruhn (2018) with 10 items was adopted for this study. For social undermining, 13 items measurement scaled was adopted which was developed by Duffy et al. (2002). The composite reliability of all measurement scales was above 0.7 , thus confirming its internal consistency reliability.

\section{Data Analysis}

Following Hayes (2017), the mediation and moderation analyses were conducted using SPSS macro. To clarify, the present study is not conceptualizing any "moderated-mediation" relationships. Thus, it does not require performing conditional analysis, analyzing moderation and mediation in a single step. The indirect effect can duly be tested through bootstrap confidence intervals (subsamples $=5000$ ). For that case, value of zero represent the null effect of hypothesis. If value of 0 falls between the upper and lower bound confidence interval, therefore we retain the null hypothesis. Otherwise, alternate hypothesis is accepted that the indirect effect of mediator in the model is significant (Hayes, 2017, Memon et al., 2018). In this case of first hypothesis, 0 fall outside of that critical region, hence, the first hypothesis is true that team mindfulness mediates the relationship between task conflict and perceived stress. 
Table 1: Indirect Effect of Task Conflict on Stress via Team Mindfulness

\begin{tabular}{l|c|c|c|c}
\hline & Indirect Effect & SE & LLCI & ULCI \\
\hline Task Conflict $\rightarrow$ Team Mindfulness $\rightarrow$ Stress & .1172 & .0268 & .0684 & .1736 \\
\hline
\end{tabular}

The moderating effect of relationship conflict was then tested. For this relationship, interaction term is statistically significant $(\mathrm{p}<0.05)$ at $95 \%$ confidence interval $(\beta=$ .1579$, SE $=.0795, p=.0483$, LLCI $=-.3147$, ULCI $=-.0012)$. This shows that the moderating effect exists in this case and the second hypothesis is also supported. Value for $\mathrm{R}$ square change was .0148 . $\mathrm{R}$ square change is the additional value of change in DV due to the moderator (Hayes, 2017).

Here in this case, the interaction term has the p value of 0.3809 which is not significant at $95 \%$ confidence interval $(\beta=-0.0491, \mathrm{SE}=.0559, p=.3809, \mathrm{LLCI}=-$ .1592 , ULCI $=.0611)$ Hence, this shows that the third hypothesis is not supported. This means that relationship conflict does not moderate between task conflict and social undermining. The summary of the hypotheses testing is provided in Table 3 .

Table 2: Results of Moderation Analysis

\begin{tabular}{l|c|c|c|c}
\multicolumn{1}{c|}{ Constructs } & Effect & SE & LLCI & ULCI \\
\hline Int_1 (Relationship Task X Task Conflict)* & -.1579 & .0795 & -.3147 & -.0012 \\
\hline Int_2 (Relationship Task X Task Conflict) & -0.491 & .0559 & -.1592 & .0611 \\
* Dependent variable $=$ perceived stress \\
** Dependent variable $=$ social undermining
\end{tabular}

Table 3: Summary of Hypothesis Testing

\begin{tabular}{|c|c|c|}
\hline Hypotheses & Hypothesis Statement & Results \\
\hline H1 & $\begin{array}{l}\text { Team mindfulness mediates the relationship between task } \\
\text { conflict and perceived stress. }\end{array}$ & Supported \\
\hline $\mathbf{H} 2$ & $\begin{array}{l}\text { Relationship conflict moderates the relationship between task } \\
\text { conflict and perceived stress. }\end{array}$ & Supported \\
\hline H3 & $\begin{array}{l}\text { Relationship conflict moderates the relationship between task } \\
\text { conflict and social undermining. }\end{array}$ & Not Supported \\
\hline
\end{tabular}

\section{Discussion and Implications}

To recapitulate, this study leverages the JD-R theory to examine (1) if in the absence of resources, role conflicts and task conflicts would lead to social undermining and perceived stress, and (2) if team mindfulness, as a personal resource, have the motivation potential that mitigates the effect. From the results, it is evident team mindfulness displayed mediating effect on the relationship between task conflicts and perceived stress. On the other hand, relationship conflict shows inconsistent results where it displays moderating effect between task conflict and perceived stress, but not with social undermining. Hence, as per the objectives of this study for testing these variables' relationship, first two hypotheses are supported while surprisingly, our third hypothesis is not supported. One possible explanation may be that on one side, task conflict benefits teams when it encourages the team to learn from the information exchanged during task disagreement (Jehn \& Bendersky, 2003; Shaw et al., 2011; de Wit et al. 2012) but on the other side, it also relates with the complex nature of relationship conflict which considerably results in more stress between employees and can be more difficult to manage than task conflict (Gerpott \& Kearney, 2017; Maltarich et al., 2017). Additionally, task conflict is not always necessarily be seen as 
negative. Task conflict can be benefits organizations because it encourages openmindedness and helps avoid the tendency toward group think that many organizations fall prey to. The key is learning how to manage task conflict effectively so that it can serve as a catalyst, rather than a hindrance, to organizational improvement (de Wit et al., 2012).

Theoretically, this study advances our understanding on the role of team mindfulness. It demonstrates that the two dimensions of cognitive and affective functions reside within team mindfulness help in in explaining the task conflicts (Good et al., 2016). This further reduces negativity and relationship rift at the workplace. With very few studies have been conducted on virtual workplace employees in emerging markets including those of South Asia, this study enhances our understanding on the behaviour of this group of employees that may prove to be a cornerstone for future work.

\section{Implications for Asian Business}

This study also has significance for practitioners in Asia organisations. With the advent of information technology, the concept of virtual workplace and virtually connected employees is a reality. In today's complex, global environment, having interdisciplinary and highly diverse virtual teams is a norm. In the light of the research findings, managers should have a better understanding that task conflict that may lead the employees towards perceived stress which may further decrease the performance of employees. Similarly, task conflict leads to relationship conflict and even that may lead to perceived stress at the workplace. Such factors may decrease the performance of employees at the workplace. Shahzad (2018) explained that organizational contextual factors are important, and they ensure the perception of procedural justice in performance management system for a workplace that would have lesser distortion of performance appraisal results. Therefore, effective leadership style is needed to address such issues for employees in the virtual workplace.

With the prevalence of Confucianism orientations in Asian organisations which shape employees' affective and normative motives, it fosters a level of competitiveness of always seeking improvement relative to oneself and to others (Kang et al., 2015). This is no difference in virtual teams. Therefore, there is a need to build and maintain virtual employees' identity and to deal effectively with unique issues such as visibility in the organisation and career paths. Virtual employees need to feel they are on par with their peers, and that their different personal and work circumstances are understood. Additionally, mindfulness interventions and training are highly useful in reducing workplace stress. (Grover et al., 2017). In this regard, providing virtual employees with the personal resources to cope with these demands and concomitantly, altering their perceptions of these demands through mindfulness training enhances the outlook of their jobs that bring about positive personal and organisation outcomes. 


\section{Conclusion}

This study is not without its limitations. Being a cross-sectional study, future studies may want to consider adopting a longitudinal design or to have multisource data collection. Additionally, this study is conducted within a particular developing country. While it provides a glimpse on the results, it is also important to note that one's attitudes as well as workplace settings would influence the perception of conflicts (Tafvelin et al., 2019). Hence, future researchers could test this model in different contexts and in different sectors. Similarly, few aspects of this model have not been addressed in this model may be explored by the future researchers. For instance, it remains to be seen that how team mindfulness affects the social undermining (Carter et al., 2018).

We will conclude this study by arguing that conflicts are inevitable in organisations, which in-turn increased the level of perceive stress and social undermining. In turn, this may reduce staff satisfaction about the job and the productivity or service rendered. Thus, early recognition of the conflict, paying attention to the conflicting parties and ensure that the causes of conflicts are addressed as soon as they are noticed are very important.

\section{References}

Algesheimer, R., Dholakia, U. M., \& Gurău, C., (2011), "Virtual team performance in a highly competitive environment", Group \& Organization Management, vol. 36, no. 2, pp. 161-190.

Amason, A. C., \& Sapienza, H. J. (1997), "The effects of top management team size and interaction norms on cognitive and affective conflict", Journal of Management, vol. 23, no. 4, pp. 495-516.

Arch, J. J., \& Craske, M. G., (2006), "Mechanisms of mindfulness: Emotion regulation following a focused breathing induction", Behaviour Research and Therapy, vol. 44, no. 12 , pp. $1849-1858$.

Baer, R. A., Smith, G. T., \& Allen, K. B., (2014), "Assessment of mindfulness by self- report: The Kentucky inventory of mindfulness skills", Assessment, vol. 11, no. 3, pp.191-206.

Baron, L., Rouleau, V., Grégoire, S., \& Baron, C., (2018), "Mindfulness and leadership flexibility", Journal of Management Development, vol. 37, no. 2, pp. 165-177.

Bettenhausen, K. L., \& Murnighan, J. K., (1991), "The development of an intragroup norm and the effects of interpersonal and structural challenges", Administrative Science Quarterly, vol. 36, no. 1, pp. 20-35.

Bishop, S. R., Lau, M., \& Shapiro, S., (2004), "Mindfulness: A proposed operational definition", Clinical Psychology: Science and Practice, vol. 11, no. 3, pp. 230-241.

Boyle, C. C., Stanton, A. L., Ganz, P. A., Crespi, C. M., \& Bower, J. E., (2017), "Improvements in emotion regulation following mindfulness meditation: Effects on depressive symptoms and perceived stress in younger breast cancer survivors", Journal of Consulting and Clinical Psychology, vol. 85, no. 4, pp. 397-402.

Brisbon, N. M., \& Lachman, M. E., (2017), "Dispositional mindfulness and memory problems: The role of perceived stress and sleep quality", Mindfulness, vol. 8, no. 2, pp. 379-386.

Brown, K. W., \& Ryan, R. M., (2003), "The benefits of being present: Mindfulness and its role in psychological well-being", Journal of Personality and Social Psychology, vol. 84, pp. 822-848. 
Bradley, B. H., Anderson, H. J., Baur, J. E., \& Klotz, A. C., (2015), "When conflict helps: Integrating evidence for beneficial conflict in groups and teams under three perspectives", Group Dynamics, vol. 19, pp. 243-272.

Cacioppe, R. L., (2017), "Integral mind flow: A process of mindfulness-in-flow to enhance individual and organization learning", The Learning Organization, vol. 24, no. 6, pp. 408-417.

Carter, N. T., Carter, D. R., \& DeChurch, L. A., (2015), "Implications of observability for the theory and measurement of emergent team phenomena", Journal of Management, vol. 44, no. 4, pp. 1398-1425.

Chaiken, S., (1980), "Heuristic versus systematic information processing and the use of source versus message cues in persuasion", Journal of Personality and Social Psychology, vol. 39, pp. 752-766.

Choi, K., \& Cho, B., (2011), "Competing hypotheses analyses of the associations between group task conflict and group relationship conflict", Journal of Organizational Behaviour, vol. 32, pp. 1106-1126.

Creswell, J. D., (2015), Biological pathways linking mindfulness with health, In Brown, K. W., Creswell, J. D., \& Ryan, R. M., Handbook of mindfulness: Theory, research, and practice, Guilford Press, New York.

Dane, E., (2011), "Paying attention to mindfulness and its effects on task performance in the workplace", Journal of Management, vol. 37, pp. 997-1018.

Dane, E., \& Brummel, B. J., (2014), "Examining workplace mindfulness and is relations to job performance and turnover intention", Human Relations, vol. 67, pp. 105-128.

David, S. K., (2018), "Mindfulness in the workplace", Strategic HR Review, vol. 17, no. 2, pp. $76-80$.

Davidson, R. J., (2010), "Empirical explorations of mindfulness: Conceptual and methodological conundrums", Emotion, vol. 10, pp. 8-11.

Davidson, R. J., \& Kaszniak, A. W., (2015), "Conceptual and methodological issues in research on mindfulness and meditation", The American Psychologist, vol. 70, pp. 581592.

Dietz, J., Fitzsimmons, S. R., Aycan, Z., Francesco, A. M., Jonsen, K., Osland, J., \& Boyacigiller, N. A., (2017), "Cross-cultural management education rebooted: Creating positive value through scientific mindfulness", Cross Cultural \& Strategic Management, vol. 24, no. 1, pp. 125-151.

De Dreu, C. K., \& Weingart, L. R., (2003), "Task versus relationship conflict, team performance, and team member satisfaction: A meta-analysis", The Journal of Applied Psychology, vol. 88, pp. 741-749.

de Wit, F. R., Greer, L. L., \& Jehn, K. A., (2012), "The paradox of intragroup conflict: A meta-analysis", The Journal of Applied Psychology, vol. 97, pp. 360-390.

Donald, J. N., Atkins P. W., Parker, P. D., (2016), "Daily stress and the benefits of mindfulness: Examining the daily and longitudinal relations between present-moment awareness and stress responses", Journal of Research in Personality, vol. 65, pp. 30-37.

Dreyfus, G., (2011), "Is mindfulness present-centered and non-judgmental? A discussion of the cognitive dimensions of mindfulness", Contemporary Buddhism, vol. 12, pp. 41-54.

Felps, W., Mitchell, T. R., \& Byington, E., (2006), "How, when, and why bad apples spoil the barrel: Negative group members and dysfunctional groups", Research in Organizational Behaviour, vol. 27, pp. 175-222.

Gerpott, F. H., \& Kearney, E., (2017), "Take It personally? Performance of diverse teams: The interplay of relationship and task conflict", Academy of Management, vol. 2017, no. 1, p. 10973.

Glomb, T. M., \& Liao, H., (2003), "Interpersonal aggression in work groups: Social influence, reciprocal, and individual effects", Academy of Management Journal, vol. 46, pp. 486-496.

Greer, L. L., Jehn, K. A., \& Mannix, E. A., (2008), "Conflict transformation: An exploration of the interrelationships between task, relationship, and process conflict", Small Group Research, vol. 39, pp. 278-302. 
Hafenbrack, A. C., Kinias, Z., \& Barsade, S. G., (2014), "Debiasing the mind through meditation mindfulness and the sunk-cost bias", Psychological Science, vol. 25, pp. 369-376.

Hayes, A. F., (2017), Introduction to mediation, moderation, and conditional process analysis: A regression-based approach, Guilford Publications, New York.

Hershcovis, M. S., (2011), "Incivility, social undermining, bullying, oh my!": A call to reconcile constructs within workplace aggression research", Journal of Organizational Behaviour, vol. 32, pp. 499-519.

Hopthrow, T., Hooper, N., Mahmood, L., Meier, B. P., \& Weger, U., (2017), "Mindfulness reduces the correspondence bias", Quarterly Journal of Experimental Psychology, vol. 70, no. 3, pp. 351-360.

Hulsheger, U. R., (2015), "Making sure that mindfulness is promoted in organizations in the right way and for the right goals", Industrial and Organizational Psychology: Perspectives on Science and Practice, vol. 8, pp. 674-679.

Jehn, K. A., (1995), "A multi method examination of the benefits and detriments of intragroup conflict", Administrative Science Quarterly, vol. 40, pp. 256-282.

Jehn, K. A., Greer, L., Levine, S., \& Szulanski, G., (2008), "The effects of conflict types, dimensions, and emergent states on group outcomes", Group Decision and Negotiation, vol. 17, pp. 465-495.

Johnson, H. H., \& Avolio, B. J., (2018), “Team psychological safety and conflict trajectories' effect on individual's team identification and satisfaction", Group \& Organization Management, vol. 70, no. 3, pp. 1-31.

Kabat-Zinn, J., (1990), Full catastrophe living: Using the wisdom of your body and mind to face stress, pain, and illness, Deltacorte, New York.

Keng, S. L., Smoski, M. J., \& Robins, C. J., (2011), "Effects of mindfulness on psychological health: A review of empirical studies", Clinical Psychology Review, vol. 31, no. 6, pp. 1041-1056.

Kiken, L. G., Garland, E. L., Bluth, K., Palsson, O. S., \& Gaylord, S. A., (2015), "From a state to a trait: Trajectories of state mindfulness in meditation during intervention predict changes in trait mindfulness", Personality and Individual Differences, vol. 81, 41-46.

Krishna, S., \& Robinson, M. D., (2015), "Maintaining an even keel: An affect-mediated model of mindfulness and hostile work behaviour", Emotion, vol. 15, pp. 579-589.

Lazarus, R. S., \& Folkman, S., (1984), Stress, appraisal, and coping, Springer, New York.

Maltarich, M. A., Kukenberger, M., Reilly, G., \& Mathieu, J., (2017), "Conflict in teams: Modelling early and late conflict states and the interactive effects of conflict processes", Group \& Organization Management, vol. 43, no. 1, pp. 6-37.

Marks, M. A., Mathieu, J. E., \& Zaccaro, S. J., (2001), "A temporally based framework and taxonomy of team processes", Academy of Management Review, vol. 26, pp. 356-376.

Masuda, A., \& Tully, E. C., (2012), "The role of mindfulness and psychological flexibility in somatization, depression, anxiety, and general psychological distress in a nonclinical college sample", Journal of Evidence-Based Complementary and Alternative Medicine, vol. 17, pp. 66-71.

McClintock, A. S., \& Anderson, T., (2013), "The application of mindfulness for interpersonal dependency: Effects of a brief intervention", Mindfulness, vol. 6, pp. 1-10.

Netemeyer, R., (2003), Scaling procedures: Issues and applications, Sage Publications, London.

Miller, J., Fletcher, K., \& Kabat-Zinn, J., (1995), "Three-year follow-up and clinical implications of a mindfulness meditation-based stress reduction intervention in the treatment of anxiety disorders", General Hospital Psychiatry, vol. 17, no. 3, pp. 192200.

Morgeson, F. P., \& Hofmann, D. A., (1999), "The structure and function of collective constructs: Implications for research and theory development", Academy of Management Review, vol. 24, pp. 249-265. 
Morrison, A. B., Goolsarran, M., Rogers, S. L., \& Jha, A. P., (2013), "Taming a wandering attention: Short-form mindfulness training in student cohorts", Frontiers in Human Neuroscience, vol. 7, pp. 1-12.

Moskowitz, J. T., Duncan, L. G., Moran, P. J., (2015), "Dispositional mindfulness in people with HIV: Associations with psychological and physical health", Personality and Individual Differences, vol. 86, pp. 88-93.

Oman, D., Shapiro, S. L., Thoresen, C. E., Plante, T. G., \& Flinders, T., (2008), "Meditation lowers stress and supports forgiveness among college students: A randomized controlled trial", Journal of American College Health, vol. 56, pp. 569-578.

Paul, S., He, F., \& Dennis, A. R., (2018), "Group atmosphere, shared understanding, and team conflict in short duration virtual teams", In Proceedings of the 51st Hawaii International Conference on System Sciences.

Rayan, A., \& Ahmad, M., (2017), "Effectiveness of mindfulness-based intervention on perceived stress, anxiety, and depression among parents of children with autism spectrum disorder", Mindfulness, vol. 8, no. 3, pp. 677-690.

Reb, J., Narayanan, J., \& Chaturvedi, S., (2014), "Leading mindfully: Two studies of the influence of supervisor trait mindfulness on employee well-being and performance", Research Collection Lee Kong Chian School of Business, vol. 5, no. 1, p.36.

Reb, J., Narayanan, J., \& Ho, Z. W., (2015), "Mindfulness at work: Antecedents and consequences of employee awareness and absent-mindedness", Mindfulness, vol. 6, no. 1 , pp.111-122.

Shahzad, M. U., (2018), "Organizational context factors influencing procedural justice in performance management system: A research framework", Journal of Management Sciences, vol. 5, no. 2, pp. 64-85.

Shapiro, S., Brown, K., \& Biegel, G., (2007), "Teaching self-care to caregivers: Effects of mindfulness-based stress reduction on the mental health of therapists in training", Training and Education in Professional Psychology, vol. 1, pp. 105-115.

Sell, B., (2008), Cultivating mindfulness in the large group, Group, vol. 32, no. 4, pp. 261272.

Simons, T. L., \& Peterson, R. S., (2000), "Task conflict and relationship conflict in top management teams: The pivotal role of intragroup trust", The Journal of Applied Psychology, vol. 85, pp. 102-111.

Slagter, H. A., Davidson, R. J., \& Lutz, A., (2011), "Mental training as a tool in the neuroscientific study of brain and cognitive plasticity", Frontiers in Human Neuroscience, vol. 5, pp. 135-146.

Smallwood, J., \& Schooler, J. W., (2015), "The science of mind wandering: Empirically navigating the stream of consciousness", Annual Review of Psychology, vol. 66, pp. 487-518.

Sutcliffe, K. M., Vogus, T. J., \& Dane, E., (2016), "Mindfulness in organizations: A crosslevel review", Annual Review of Organizational Psychology and Organizational Behaviour, vol. 3, pp. 55-81.

Tan, C. M., (2012), Search inside yourself - The unexpected path to achieving success, happiness, and world peace, Harper Collins Publishers, New York.

Tidd, S. T., McIntyre, H. H., \& Friedman, R. A., (2004), "The importance of role ambiguity and trust in conflict perception: Unpacking the task conflict to relationship conflict linkage", International Journal of Conflict Management, vol. 15, pp. 364-380.

Todorova, G., Bear, J. B., \& Weingart, L. R., (2014), "Can conflict be energizing? A study of task conflict, positive emotions, and job satisfaction", The Journal of Applied Psychology, vol. 99, pp. 451-467.

Tsai, M. H., \& Bendersky, C., (2016), "The pursuit of information sharing: Expressing task conflicts as debates vs. disagreements increases perceived receptivity to dissenting opinions in groups", Organization Science, vol. 27, pp. 141-156.

Turner, N., Kutsch, E., \& Leybourne, S. A., (2016), "Rethinking project reliability using the ambidexterity and mindfulness perspectives", International Journal of Managing Projects in Business, vol. 9, no. 4, pp. 845-864. 
van Knippenberg, D., van Ginkel, W. P., \& Homan, A. C., (2013), "Diversity mind sets and the performance of diverse teams", Organizational Behaviour and Human Decision Processes, vol. 121, pp. 183-193.

Vogus, T. J., \& Sutcliffe, K. M., (2012), "Organizational mindfulness and mindful organizing: Are conciliation and path forward", Academy of Management Learning \& Education, vol. 11, pp. 722-735.

Weare, K., (2014), Evidence for mindfulness: Impacts on the wellbeing and performance of school staff, Mindfulness of Schools Projects University of Exeter, Southampton.

Weick, K. E., \& Putnam, T., (2006), "Organizing for mindfulness Eastern wisdom and Western knowledge", Journal of Management Inquiry, vol. 15, pp. 275-287.

Weick, K. E., \& Roberts, K. H., (1993), "Collective mind in organizations: Heedful interrelating on flight decks", Administrative Science Quarterly, vol. 38, pp. 357-381.

Weingart, L. R., Behfar, K. J., Bendersky, C., Todorova, G., \& Jehn, K. A., (2015), "The directness and oppositional intensity of conflict expression", Academy of Management Review, vol. 40, pp. 235-262.

Weinstein, N., Brown, K. W., \& Ryan, R. M., (2009), "A multi-method examination of the effects of mindfulness on stress attribution, coping, and emotional wellbeing", Journal of Research in Personality, vol. 43, pp. 374-385.

Wolff, S. B., (2014), Emotion and mindfulness: Using emotion as information to raise collective performance, In Emotions and the organizational fabric, Emerald Group Publishing Limited, London.

Wu, L. Z., Ferris, D. L., Kwan, H. K., Chiang, F., Snape, E., \& Liang, L. H., (2015), "Breaking (or making) the silence: How goal interdependence and social skill predict being ostracized", Organizational Behaviour and Human Decision Processes, vol. 131, pp. 51-66.

Xu, W., Zhou, Y., Fu, Z., \& Rodriguez, M., (2017), "Relationships between dispositional mindfulness, self-acceptance, perceived stress, and psychological symptoms in advanced gastrointestinal cancer patients", Psych oncology, vol. 26, no. 12, pp. 21572161.

Yu, L., \& Zellmer-Bruhn, M., (2018), "Introducing team mindfulness and considering its safeguard role against conflict transformation and social undermining", Academy of Management Journal, vol. 61, no. 1, pp. 324-347.

Zeidan, F., Johnson, S. K., Gordon, N. S., \& Goolkasian, P., (2010), "Effects of brief and sham mindfulness meditation on mood and cardiovascular variables", The Journal of Alternative and Complementary Medicine, vol. 16, 867-873. 